\title{
Pharmacology and toxicology of diphenyl diselenide in several biological models
}

\author{
R.M. Rosa ${ }^{1}$, R. Roesler ${ }^{2}$, \\ A.L. Braga ${ }^{4}$, J. Saffi ${ }^{1,3}$ \\ and J.A.P. Henriques ${ }^{1,3}$
}

\author{
${ }^{1}$ Departamento de Biofísica, Instituto de Biociências, \\ ${ }^{2}$ Departamento de Farmacologia, Instituto de Ciências Básicas da Saúde, \\ Universidade Federal do Rio Grande do Sul, Porto Alegre, RS, Brasil \\ ${ }^{3}$ Laboratório de Genética Toxicológica, Universidade Luterana do Brasil, \\ Canoas, RS, Brasil \\ ${ }^{4}$ Instituto de Química, Universidade Federal de Santa Maria, Santa Maria, \\ RS, Brasil
}

\author{
Correspondence \\ J.A.P. Henriques \\ Agronomia, UFRGS \\ Av. Bento Gonçalves, 9500 \\ Ed. 43422, Laboratório 210 \\ 91501-970 Porto Alegre, RS \\ Brasil \\ Fax: +55-51-3316-7309 \\ E-mail: pegas@cbiot.ufrgs.br \\ Research supported by CNPq, \\ CAPES, and GENOTOX (Genotoxicity \\ Laboratory, Instituto Royal, \\ Brazil). R.M. Rosa is the \\ recipient of a doctoral grant \\ from CAPES
}

Received January 18, 2007

Accepted May 21, 2007

\begin{abstract}
The pharmacology of synthetic organoselenium compounds indicates that they can be used as antioxidants, enzyme inhibitors, neuroprotectors, anti-tumor and anti-infectious agents, and immunomodulators. In this review, we focus on the effects of diphenyl diselenide (DPDS) in various biological model organisms. DPDS possesses antioxidant activity, confirmed in several in vitro and in vivo systems, and thus has a protective effect against hepatic, renal and gastric injuries, in addition to its neuroprotective activity. The activity of the compound on the central nervous system has been studied since DPDS has lipophilic characteristics, increasing adenylyl cyclase activity and inhibiting glutamate and MK- 801 binding to rat synaptic membranes. Systemic administration facilitates the formation of long-term object recognition memory in mice and has a protective effect against brain ischemia and on reserpine-induced orofacial dyskinesia in rats. On the other hand, DPDS may be toxic, mainly because of its interaction with thiol groups. In the yeast Saccharomyces cerevisiae, the molecule acts as a pro-oxidant by depleting free glutathione. Administration to mice during cadmium intoxication has the opposite effect, reducing oxidative stress in various tissues. DPDS is a potent inhibitor of $\delta$-aminolevulinate dehydratase and chronic exposure to high doses of this compound has central effects on mouse brain, as well as liver and renal toxicity. Genotoxicity of this compound has been assessed in bacteria, haploid and diploid yeast and in a tumor cell line.
\end{abstract}

\section{Introduction}

The element selenium was discovered in 1818 by the Swedish chemist Berzelius and was named after the Greek goddess of the
Key words

- Diphenyl diselenide

- Organoselenium

- Antioxidants

- Neuroprotection

- Saccharomyces cerevisiae

- Mutagenesis moon, Selene. First reports were related to its toxicity. Although evidence was obtained as early as 1842 for the toxicity of selenium, the first authentic written record of selenium poisoning was reported in 1856 by Madison, 
an army surgeon stationed at Fort Randall, then in the Nebraska territory (1). He described a fatal disease among horses grazing certain areas near the fort. In 1929, investigations started to study toxic grains at the South Dakota Experimental Station and in 1933 the toxic principle in these grains was suggested to be selenium, which was confirmed a year later. The element was reported to be a potent carcinogen in 1943 (2, 3 ). Selenium was thus considered to be an absolute poison until Schwarz and Foltz identified it as a micronutrient for bacteria, mammals and birds (1). After years of empirical studies on selenium deficiency syndromes in animal models, selenium biochemistry emerged in 1973, when the bacterial enzymes formate dehydrogenase and glycine reductase were reported to contain selenium. At the same time, this atom was found in the active site of the antioxidant enzyme glutathione peroxidase (GPX) in mammals (1). The number of selenoproteins identified has grown substantially in recent years and molecular mechanisms and regulatory pathways of seleno amino acid incorporation have been elucidated (2).

The biological importance of selenium and its inorganic forms led to the development of pharmacologically active organoselenium (OS) compounds with low toxicity, since the selenium atom was not delivered to the intracellular selenium pool. Although the first synthetic OS compound, diethyl diselenide, was prepared by Lowig as early as in 1836 , the highly malodorous nature of selenium compounds, difficulties in purification, and the instability of many of the derivatives hampered further developments. The discovery of several useful new reactions and a variety of novel structures with unusual properties led to further OS development. Interest in the use of these molecules in biochemistry started with the findings that they are much less toxic than inor- ganic selenium species (1).

Diphenyl diselenide (DPDS; Figure 1) (4) is a simple and stable OS compound. It is an electrophilic reagent used in the synthesis of a variety of pharmacologically active OS compounds (4). Recently, the biological activities of DPDS have been studied and this compound has become a good candidate for therapeutic purposes. In this review we provide a comprehensive coverage of the toxicology and pharmacology of this molecule.

\section{Toxicology}

Although the molecular mechanisms underlying selenium toxicity are still poorly understood, Painter (see Ref. 1) proposed that it could be related to the oxidation of thiols of biological importance. The interaction of inorganic selenium with thiols was demonstrated experimentally by Tsen and Tappel (5), who showed that selenite catalytically increased the oxidation of glutathione. Subsequently, the effectiveness of OS compounds as catalytic oxidants of thiols was reported (5-9). Inorganic and organic forms of selenium can also increase thiol oxidation by accelerating electron transfer from thiols to oxidized acceptors such as cytochrome c and methylene blue (8).

The mechanism of oxidation of thiol groups in low- and high-molecular weight molecules by selenium varies with the chemical structure of the compounds and can involve the formation of selenoxides, selenotrisulfides and selenylsulfide $(10,11)$. OS compounds such as selenocystine and a variety of diselenides can react with thiols such as cysteine, dithiothreitol (DTT) and reduced glutathione (GSH) to produce selenocysteine and selenols, respectively, and disulfides. The interaction between DPDS and thiol groups has been investigated in several biological models, such as the enzyme 
$\delta$-aminolevulinate dehydratase (ALA-D) from various sources, strains of Saccharomyces cerevisiae defective in GSH biosynthesis, and in in vitro systems.

\section{Interaction with $\delta$-aminolevulinate dehydratase}

ALA-D, or porphobilinogen synthase, is an enzyme sensitive to sulfydryl (SH)-blocking agents that participates in the second step of heme, chlorophyll and corrin biosynthesis $(11,12)$. It catalyzes the condensation of two molecules of 5-aminolevulinic acid to porphobilinogen, thus playing an essential role in animals and photosynthetic organisms $(11,12)$. ALA-D inhibition inhibits heme biosynthesis, resulting in accumulation of aminolevulinic acid, which affects aerobic metabolism, and has some pro-oxidant activity (13). Inhibition of heme biosynthesis may disturb the production of cytochrome P450, fundamental to metabolism.
The investigation of the effects of DPDS treatment on ALA-D activity is of particular significance from an academic and toxicological point of view because of the importance of reduced thiol groups for ALA-D activity and the oxidant properties of organic and inorganic selenium compounds. Studies have indicated whether this enzyme is a potential target for DPDS and whether it can be considered a marker for OS exposure, as was found for lead intoxication.

The first study was carried out in vitro using ALA-D purified from liver, kidney and brain of adult rats. DPDS, as well as other diselenide bond-containing compounds, did indeed have an inhibitory potential on ALA-D, even without pre-incubation. However, after pre-incubation of the enzyme preparation with DPDS, inhibition was significantly stronger. The effect was reversed in a concentration-dependent manner by DTT treatment, which protects $\mathrm{SH}$ groups of the enzyme, and also by GSH, the

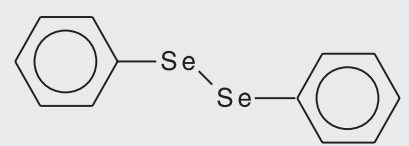

Diphenyl diselenide

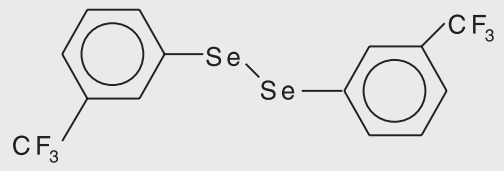

3,3'-Ditrifluoromethyl-diphenyl diselenide

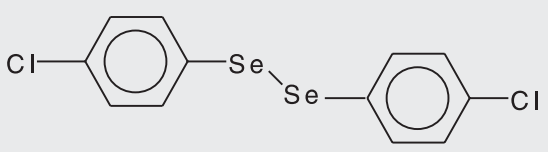

p-Chloro-diphenyl diselenide

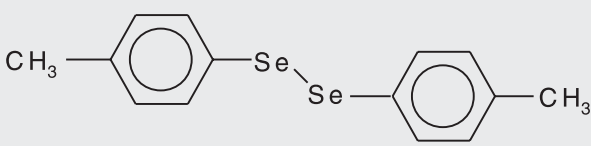

p-Methyl-diphenyl diselenide

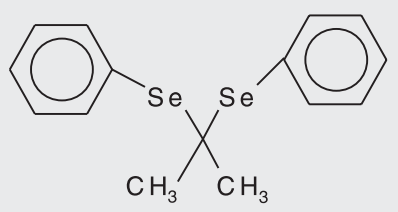

Propryl-2,2-diphenyl diselenide

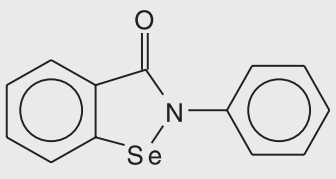

Ebselen
Figure 1. Chemical structure of diphenyl diselenide, some diphenyl diselenide derivatives and ebselen. 
main cellular thiol (14). Moreover, the inhibitory action of propyl-2-methoxy-2-phenyl selenide and propyl-2,2-diphenyl diselenide (Figure 1) on ALA-D activity seems to be due to their decomposition to DPDS (14). Other OS compounds such as phenyl selenoacetylene inhibit ALA-D in vitro via conversion to DPDS (15).

The mechanism underlying the inhibitory effect of DPDS is related to oxidation of essential cysteinyl residues located at the active site of the enzyme. Since oxyradical scavengers do not interfere with the inhibitory effect of the tested compounds, DPDS apparently acts by oxidizing cysteinyl residues in a similar way to that described for low-molecular weight thiols (14). Based on this evidence, Maciel and co-workers (16) showed that DPDS inhibits ALA-D from liver, kidney and brain of mice in vivo. The effects were tissue-specific and dependent on exposure protocol (single dose or chronic treatment). The acute treatment of mice inhibited the activity of ALA-D from liver and brain but not kidney. After chronic exposure, brain and liver ALA-D were inhibited in a dose-dependent manner, with the effects being greater in liver than in brain. One interesting finding is that the treatment specifically affects enzyme activity without reducing the total content of non-protein $\mathrm{SH}$ groups. In contrast to in vitro results (8), DTT could not completely reactivate the inhibited enzyme, suggesting that the oxidation caused by organoselenium might have altered the enzyme conformation in such a way that DTT could no longer reactivate it $(14,16)$.

DPDS inhibits mammalian ALA-D but not the plant enzyme. This is presumably related to differences in the primary structure of these enzymes, i.e., in the quantity and spatial proximity of cysteinyl residues within the protein. The mammalian enzyme possesses two distinct classes of zinc-bind- ing sites, one containing a single cysteine residue and the other four cysteine residues, whereas the plant enzyme has no cysteine residues in these regions. This led Rocha and co-workers $(17,18)$ to propose a mechanism for the differential action of DPDS. In the first step, enzyme reaction with DPDS gives an unstable intermediate of the enzyme-Cys$\mathrm{S}-\mathrm{SePh}$ and selenophenol type, probably due to a thiol nucleophilic attack in the selenium atom of DPDS. Subsequently, the other cysteinyl residue, due to its close spatial proximity to the more reactive residue, attacks the sulfurselenium bond of the intermediate, producing the oxidized enzyme (inactive), and regenerates a second molecule of selenophenol. Support for this mechanism has been obtained using low-molecular weight thiol-containing molecules. The selenophenol molecules formed after reaction with the thiol group are oxidized back to DPDS by atmospheric $\mathrm{O}_{2}$. The oxidation of selenophenol helps to explain the previous observation that the inhibitory effect on rat ALA-D decreases considerably in an anaerobic atmosphere $(17,18)$.

In agreement with these observations, enzyme inhibition in human erythrocytes can be avoided by mercaptan DTT and the activity of inhibited ALA-D can be restored by treatment with this compound. However, the inhibitory effect was not reversed by GSH; even $3 \mathrm{mM}$ GSH gave only a modest increase in ALA-D activity that had been inhibited by 40 and $100 \mu \mathrm{M}$ DPDS (19). These results clearly reinforce the suggestion that DPDS inhibits ALA-D in human blood by interacting with cysteinyl residues that are important for enzyme activity. The importance of thiol groups for ALA-D catalysis is well known (20). In this case, DTT was more protective than GSH; only the more hydrophobic SH-reducing agent is able to reactivate $\mathrm{SH}$ groups localized in the deeper regions of the enzyme. Alternatively, 
the oxidation caused by DPDS in ALA-D may modify enzyme conformation in such a way that GSH is unable to reactivate the enzyme. In this manner, in vitro DPDS inactivates human erythrocyte ALA-D by interacting with the SH groups essential to the enzyme (19).

As pointed out above, OS compounds can interact directly with low-molecular weight thiols, oxidizing them to disulfides that in turn oxidize cysteinyl residues in proteins. ALA-D is an SH-containing enzyme that is extremely sensitive to oxidizing agents and thus represents an excellent tool to study this type of interaction. DPDS, in oxidizing essential $\mathrm{SH}$ groups from ALA-D, is converted into a selenol and the results obtained with mammalian ALA-D and DPDS suggest that proteins containing cysteinyl residues in close spatial proximity in their three-dimensional structure will react more promptly with DPDS. Recently, it was pointed out that this OS compound does not inhibit mouse hepatic ALA-D by an oxidative stress-mediated mechanism, since the levels of thiobarbituric reactive substances (TBARS), a marker of oxidative damage, were not increased (20). The cellular toxicity of this compound may thus be related, at least in part, to the oxidation of vicinal $\mathrm{SH}$ groups of target proteins. In addition, ALA$\mathrm{D}$ has been demonstrated to be a potential molecular target for selenium and OS intoxication.

\section{Pro-oxidant activity in yeast}

Since DPDS has high thiol peroxidase and GPX mimetic activities, we investigated its antioxidant properties using several in vitro assays and mutant strains of Saccharomyces cerevisiae deficient in superoxide dismutase, GSH biosynthesis and the yAP-1 transcription factor. Unexpectedly, DPDS per se had no cytotoxic effects on S. cerevi- siae. However, it sensitized yeast cells to oxidative mutagens, hydrogen peroxide, paraquat, tert-butyl-hydroperoxide, and sodium nitrite, suggesting that it has an indirect pro-oxidant effect (21). In spite of this lack of antioxidant defense, the response of all strains of $S$. cerevisiae tested was identi$\mathrm{cal}$, indicating the existence of a general, but not necessarily nonspecific, mechanism of indirect cytotoxicity. The GSH constitutes the common and main defense system against reactive oxygen species (ROS). This molecule also contributes to detoxification of electrophilic compounds, sequestration of toxic metals and modulation of the cellular redox and thiol-disulfide status of proteins (22).

Measurement of GSH in yeast cells treated with the OS molecule confirmed that this drug depleted cellular GSH without increasing GSH oxidation rate, explaining the pro-oxidant effect. Accordingly, the DPDS pro-oxidant activity could be lowered by $\mathrm{N}$ acetylcysteine pre-treatment, increasing GSH levels in yeast (21).

We have frequently employed a set of mutant strains involved in GSH biosynthesis in our investigations. The yeast gshl mutant is unable to synthesize the first dipeptide intermediate of GSH and, lacking endogenous GSH synthesis, requires exogenous glutathione to survive and grow in minimal media. When a second mutation, $\operatorname{lwg} 1-1$, is introduced into the gshl mutant, the resulting double mutant does not require any exogenous glutathione since the $l w g l$ missense mutation, affecting the PRO2 gene and encoding an altered $\gamma$-glutamyl phosphate reductase, can synthesize a small amount of $\gamma$ glutamyl-cysteinyl dipeptide, thus allowing synthesis of a minimal amount of GSH. The differential response to DPDS of the gshl mutant of low GSH content and of the double mutant gshl lwg1-1 confirms the involvement of GSH in protection against this OS in 
a dose-dependent manner (21).

The thiol moiety of GSH also has unique redox and strong nucleophilic properties, permitting its conjugation with electrophilic compounds, xenobiotics in particular (23). DPDS, an electrophilic molecule, is able to form an as yet undescribed GSH adduct, most probably by conjugating via nucleophilic attack to the thiol moiety of GSH; this reaction apparently occurs spontaneously in vitro and is predicted to result in a reduced state of one or both selenium moieties in DPDS. This reaction is more likely than a reduction of the diselenide bond by GSH, which is not favored since the redox potential of GSH is much higher than that of the diselenide bond $(21,23)$. This phenomenon would explain the depletion of intracellular free GSH by DPDS that results in the observed pro-oxidant properties of the drug, i.e., sensitization of DPDS-pre-treated yeast cells, regardless of their genetic endowment with anti-oxidant defense mechanisms, to an oxidative mutagen challenge.

Maciel and co-workers (16) observed that DTT, GSH, and other thiols could be oxi-

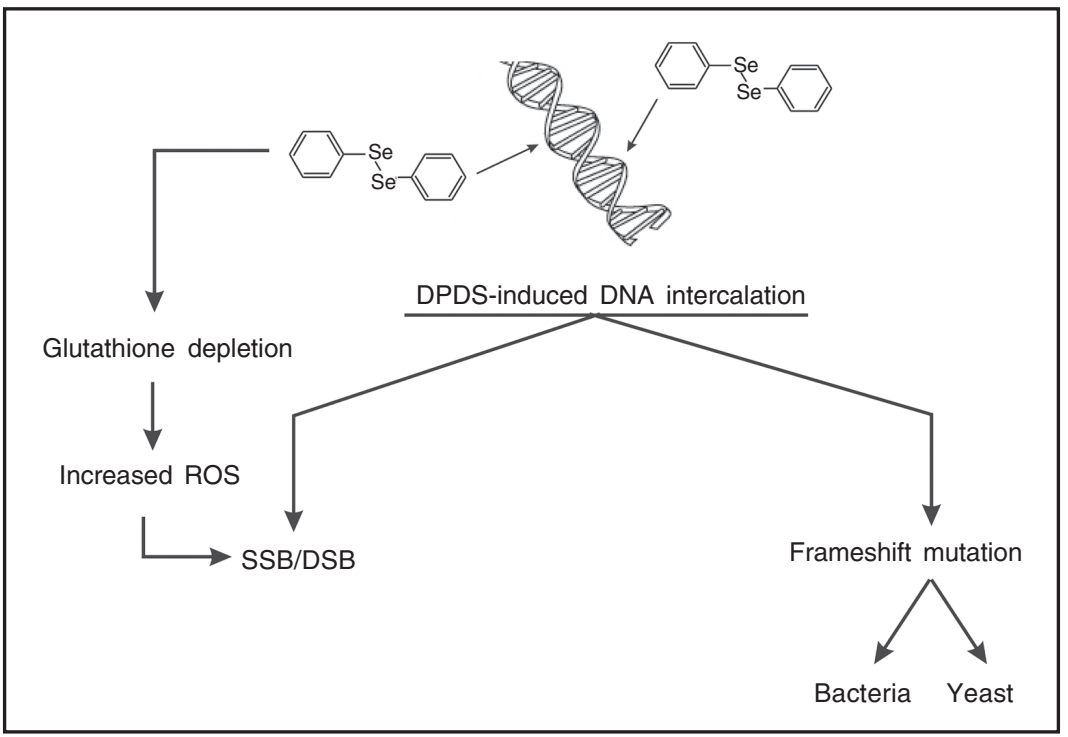

Figure 2. A possible model of the genotoxic mechanism of action of diphenyl diselenide (DPDS). ROS $=$ reactive oxygen species; $S S B=$ single-strand breaks; $D S B=$ doublestrand breaks. dized by DPDS, but that oxidation of DTT is favored over oxidation of GSH and cysteine. In the interaction between ALA-D and DPDS, oxidation is the main mechanism by which DPDS indirectly acts as a pro-oxidant by enzyme inhibition. In yeast we could not show accumulation of extracellular oxidized glutathione (GSSG) after DPDS treatment, as would be expected after direct reduction of the diselenide bond. We suggest, therefore, that the DPDS-induced pro-oxidant effect in yeast is a direct result of GSH depletion via the production of DPDS-GSH adducts.

\section{Genetic toxicology}

Our group has also investigated the potential genotoxicity of DPDS. This was deemed important since DPDS is used as an intermediate and reagent in organic syntheses, which increases the risk of human exposure in the workplace. This information is also very important to evaluate the safety of possible future pharmacological applications of the compound. The genotoxicity of DPDS has been assayed in Salmonella typhimurium and in the simple eukaryote $S$. cerevisiae, whose mutagenesis and DNA repair mechanisms were assessed using haploid strains, whereas recombinogenesis was tested in a diploid strain (4).

We suggested also that the mutagenic effect of DPDS is an indirect effect mediated by free radicals. DPDS was able to strongly enhance the oxidative mutagenesis induced by hydrogen peroxide in $S$. typhimurium TA102, which has a proven ability to detect mutagens that generate ROS and cause oxidative DNA damage. A modulatory (enhancer) role in the effect of oxidative mutagens is suggested for DPDS (Figure 2). Moreover, it is known that DPDS acts as a pro-oxidant in yeast strains, causing GSH depletion without increasing the rate of GSH 
oxidation (22). Thus, as expected, N-acetylcysteine, a GSH biosynthesis precursor, abolished the mutagenicity of DPDS in yeast, probably by conjugation with DPDS, blocking its DNA damaging potential.

To gain insight into the mechanisms of the genotoxic action of DPDS, we have studied the response of $S$. cerevisiae mutants defective in DNA repair to treatment with this OS compound. Mutants defective in excision-resynthesis repair ( $\mathrm{rad} 3-\mathrm{e} 5, \mathrm{radl} \Delta)$, in error-prone repair $(\mathrm{rad} 6 \Delta)$ and in recombinational repair ( $\mathrm{rad52}-1$ ) were used in this investigation. In this respect, the single mutants rad3-e5 and $\mathrm{radl} \Delta$, blocked in excision repair, and rad6 6 , defective in the mutagenic repair pathway, showed practically the same sensitivity as the wild-type strain. The hypersensitivity of the rad52-1 mutant strain suggests that recombinational repair is critical for the processing of potentially lethal genetic lesions resulting from DPDSinduced DNA damage. Thus, it appears that the OS compound probably induces single (SSB)- and/or double-strand breaks (DSB) in DNA (4).

The cytotoxic responses of the single mutant rad52-1 and double mutant rad3-e5 rad52-1 to DPDS are identical, which is a consequence of the absence of the RAD52 pathway. In $S$. cerevisiae, members of the $R A D 52$ epitasis group are indispensable for successful meiotic and mitotic recombination and survival after treatment with ionizing radiations, alkylating agents, some oxidative mutagens, and cross-linking agents (24). These results suggest that the DSB repair system is the main pathway required to overcome the induced lesions, whereas the excision repair and mutagenic systems are not primarily involved.

In order to examine the contribution of the base excision DNA repair pathway (BER) to DPDS-induced DNA damage, several single, double, triple and quadruple mutants were evaluated regarding survival of their mutation rate following exposure to DPDS. Figure 3 shows that the recombination-deficient rad52 mutant strain presents high sensitivity to DPDS, whereas the other mutants showed the same sensitivity as the wild-type strain. The quadruple mutant $n t g 1$ ntg2 apn1 rad52 had the same sensitivity as the single mutant rad52, supporting the participation of the recombination pathway in defense against genotoxic lesions generated by DPDS.

The results shown in Table 1 suggest that DPDS treatment increases the mutation rate in BER-deficient strains. The increase in the frequency of forward mutation induced by DPDS in the quadruple mutant blocked in both BER and nucleotide excision repair (NER) (ntg1 ntg2 apn1 radl) suggests that an error-prone pathway repairs (some of) the DNA lesions. However, the quadruple mutant for BER and translesion synthesis (ntgl ntg2 apn1 rev3), after DPDS exposure, shows induction of forward mutation. In this respect, the results of mutagenesis, also supported by the resistance of the single mutant rev3 $\Delta$, show that other translesion enzymes, like Rad30p (24), contribute to the cell's DPDS tolerance. Furthermore, the increase in the frequency of forward mutation induced by this molecule in the quadruple mutant for BER and recombinational repair (ntg1 ntg2 apn1 rad52) suggest an interaction of different DNA repair pathways related to the response to DPDS.

On this basis, our findings suggest that the $\mathrm{N}$-glycosylases and AP-lyases of the BER pathway, which primarily involves the repair of small, helix non-distorting base lesions, abasic sites, and oxidative DNA damage, have a crucial role in preventing the oxidative mutagenesis induced by this molecule. However, the recombinational repair system is the main pathway required to overcome the lesions generated by the oxidative 
Figure 3. Survival of Saccharomyces cerevisiae strains deficient in several DNA repair pathways after treatment with different doses of diphenyl diselenide (DPDS) during exponential growth in liquid-rich medium.

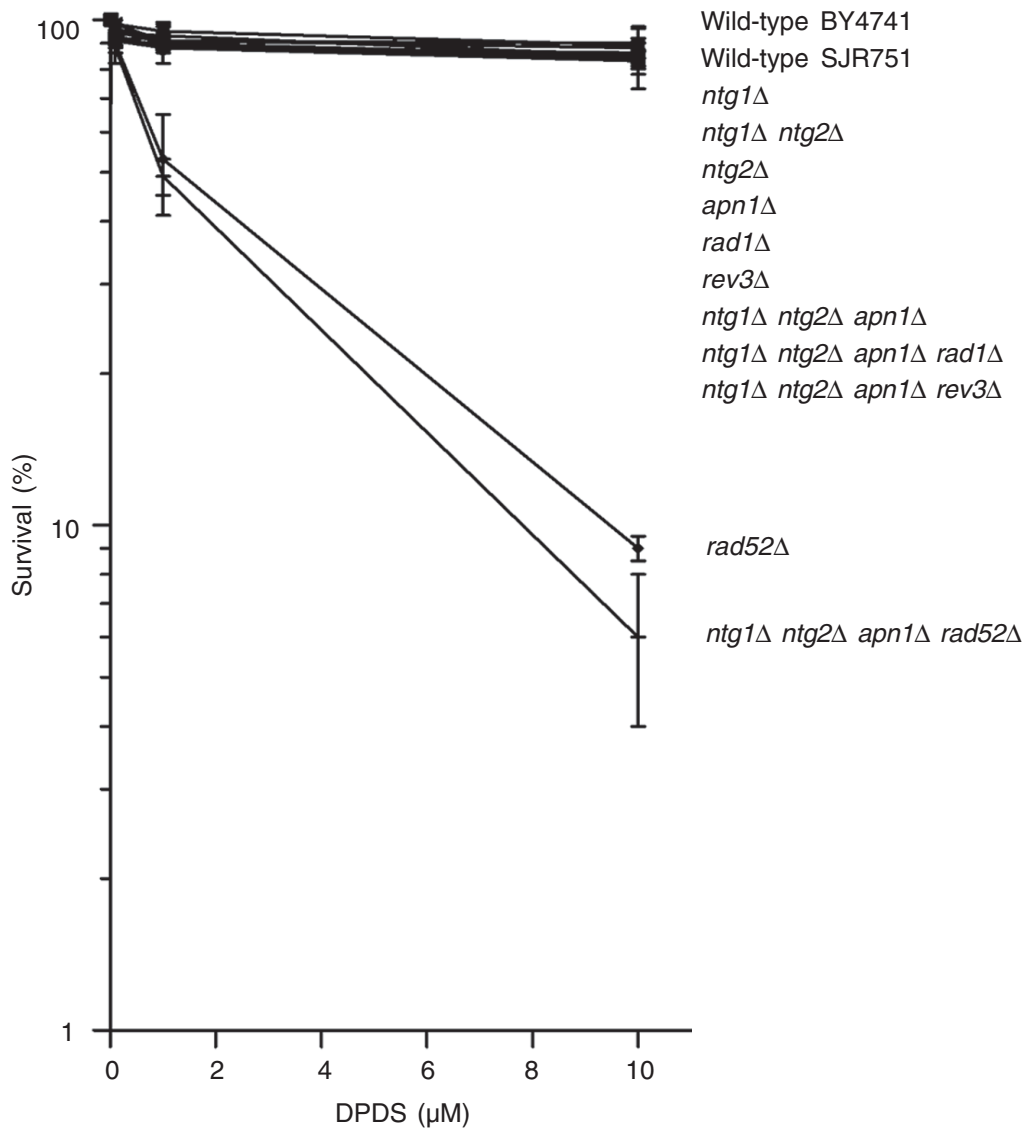

Table 1. Induction of forward mutation of the CAN1 locus (Can ${ }^{r}$ mutants per $10^{8}$ survivors) in haploid strains of Saccharomyces cerevisiae defective in DNA repair pathways, after diphenyl diselenide (DPDS) treatment during exponential growth in liquid-rich medium containing DPDS at desired concentrations.

\begin{tabular}{|c|c|c|c|c|c|}
\hline \multirow{2}{*}{$\begin{array}{l}\text { Relevant genotype/ } \\
\text { DPDS exposure }\end{array}$} & \multicolumn{5}{|c|}{ Mutation rate (Can ${ }^{r}$ mutants per $10^{8}$ survivors) } \\
\hline & 0 & $0.01 \mathrm{mM}$ & $0.1 \mathrm{mM}$ & $1 \mathrm{mM}$ & $10 \mathrm{mM}$ \\
\hline Wild-type BY4741 & $0.22 \pm 0.09$ & $0.32 \pm 0.10$ & $0.39 \pm 0.11$ & $0.16 \pm 0.05$ & $0.28 \pm 0.09$ \\
\hline $\operatorname{rad} 1 \Delta$ & $0.26 \pm 0.12$ & $0.34 \pm 0.11$ & $0.20 \pm 0.05$ & $0.29 \pm 0.10$ & $0.31 \pm 0.06$ \\
\hline rev3s & $0.38 \pm 0.02$ & $0.41 \pm 0.05$ & $0.41 \pm 0.08$ & $0.45 \pm 0.10$ & $0.48 \pm 0.10$ \\
\hline $\operatorname{rad52\Delta }$ & $0.31 \pm 0.08$ & $0.53 \pm 0.07^{*}$ & $0.85 \pm 0.06^{*}$ & $1.12 \pm 0.36^{*}$ & $1.52 \pm 0.10^{*}$ \\
\hline Wild-type SJR751 & $3.8 \pm 0.70$ & $4.1 \pm 1.10$ & $2.9 \pm 0.80$ & $5.0 \pm 2.10$ & $4.8 \pm 1.90$ \\
\hline$n \operatorname{tg} 1 \Delta$ & $9.5 \pm 1.34$ & $8.0 \pm 1.77$ & $14.3 \pm 2.85$ & $24.3 \pm 5.47^{*}$ & $31.5 \pm 9.44^{*}$ \\
\hline$n \operatorname{tg} 2 \Delta$ & $11.2 \pm 0.90$ & $12.5 \pm 0.70$ & $10.9 \pm 2.10$ & $18.4 \pm 1.80$ & $26.9 \pm 0.55^{*}$ \\
\hline$n \operatorname{tg} 1 \Delta$ ntg2 2 & $18.8 \pm 2.44$ & $21.5 \pm 3.00$ & $14.9 \pm 1.20$ & $52.4 \pm 6.44^{*}$ & $72.0 \pm 1.00^{*}$ \\
\hline$n \operatorname{tg} 1 \Delta$ ntg2 $2 \Delta$ apn1 $1 \Delta$ & $12.3 \pm 0.50$ & $18.8 \pm 2.30$ & $15.4 \pm 2.47$ & $32.9 \pm 5.00^{*}$ & $55.8 \pm 9.00^{\star}$ \\
\hline 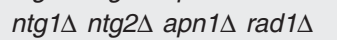 & $259.0 \pm 21.30$ & $312.2 \pm 18.47^{*}$ & $405.8 \pm 21.00^{*}$ & $667.1 \pm 50.45^{\star}$ & $730.0 \pm 81.00^{*}$ \\
\hline 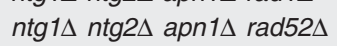 & $85.0 \pm 14.70$ & $159.8 \pm 9.20^{*}$ & $232.9 \pm 21.30^{*}$ & $389.8 \pm 62.00^{*}$ & $400.7 \pm 32.10^{*}$ \\
\hline 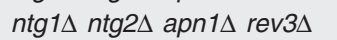 & $168.4 \pm 12.80$ & $258.1 \pm 22.00^{*}$ & $325.7 \pm 6.47^{*}$ & $554.1 \pm 18.00^{*}$ & $861.3 \pm 14.80^{*}$ \\
\hline
\end{tabular}

Data are reported as means \pm SD for 4 independent experiments carried out in triplicate. The strains rad1 $\Delta$, rev $3 \Delta$, and rad52 $\Delta$ are derivatives of the wild-type BY4741, whereas the other mutants are isogenic to strain SJR751.

${ }^{*} \mathrm{P}<0.05$ compared to DPDS non-treated cells (ANOVA followed by the Tukey test). 
damage - DNA DSB and closely located SSB - or by the SSB repair process that can, in turn, result in DSB - and rescue the survival after DPDS exposure.

Although oxidative damage can be the prime mechanism explaining the genotoxicity of this molecule in yeast, a possible intercalant effect may be also involved in the genotoxic effect. DPDS cytotoxicity may be linked to its ability to intercalate into DNA. As observed in the Ames test, DPDS clearly caused frame shift mutations only in exponentially growing cells of $S$. cerevisiae. Since chemical compounds with planar topologies and electrophilicity may intercalate between DNA bases, the mutagenic response is observed mainly as frame shift mutagenicity in microbial systems. DPDS is an electrophilic molecule with an aromatic planar structure, which induces frame shift mutation only during cellular growth, when the access to DNA is facilitated; we believe that this compound is a weak intercalator mutagen. Frame shift mutations induced by DNA-intercalating drugs have been correlated with DNA strand breaks induced by inhibition of DNA topoisomerases. Since DNA topoisomerase II inhibition induces breaks which are repaired almost exclusively by Rad52-dependent homologous recombination in yeast, the high sensitivity of the rad52 mutant could involve, at least in part, the interference of DPDS with topoisomerase II activity (24). Thus, the putative intercalant effect of DPDS may involve strand break generation by the action of topoisomerases.

In view of its genotoxic properties in microorganisms, we investigated whether DPDS might be inducing DNA damage in MCF7 cells, a mammary adenocarcinoma cell line, using the in vitro alkaline comet assay. The alkaline version of the comet assay detects primary (repairable) DNA SSB and DSB and alkali-labile sites. DPDS did not generate significant DNA damage in a dose-response manner (Figure 4). In addition, it can be seen that pre-treatment with DPDS potentiated the DNA damage induced by hydrogen peroxide, supporting the view of a clear pro-oxidant ability (Figure 5). This

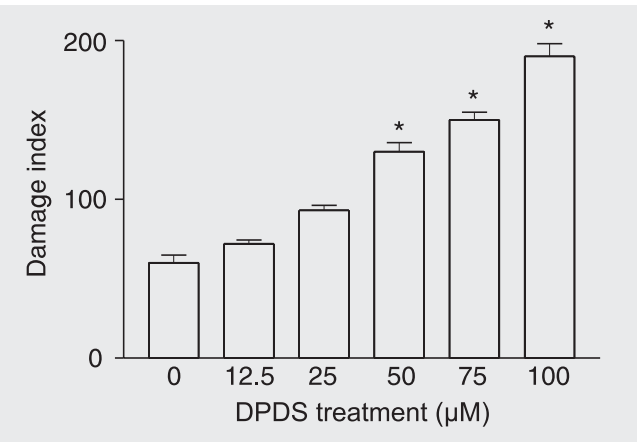

Figure 4. Genotoxicity of diphenyl diselenide (DPDS) treatment for $3 \mathrm{~h}$ in serum-free medium to the MCF7 cell line evaluated by the comet assay. Data are reported as means \pm SD for 6 independent experiments. ${ }^{*} \mathrm{P}<0.05$ compared to control (ANOVA followed by the Tukey test). Positive control: $40 \mu \mathrm{M}$ methylmethanesulfonate. Damage index is an arbitrary score calculated from cells in different damage classes, which are classified in the visual score by the measurement of DNA migration length and on the amount of DNA in the tail.

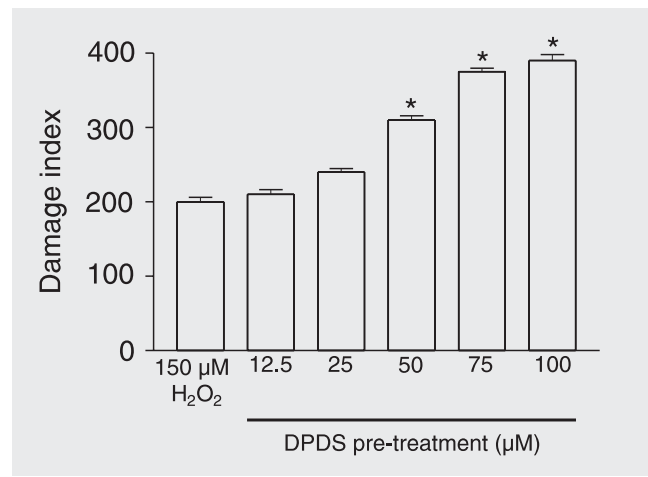

Figure 5. Pro-oxidant effect of treatment with diphenyl diselenide (DPDS) for $3 \mathrm{~h}$ in serum-free medium on the genotoxicity of $150 \mu \mathrm{M} \mathrm{H} \mathrm{H}_{2} \mathrm{O}_{2}$ to the MCF7 cell line evaluated by the comet assay. Data are reported as means \pm SD for 6 independent experiments. ${ }^{*} P<0.05$ compared to cells treated only with hydrogen peroxide (one-way ANOVA followed by the Tukey test). Damage index is an arbitrary score calculated from cells in different damage classes, which are classified in the visual score by the measurement of DNA migration length and on the amount of DNA in the tail. 
finding supports the genotoxic effects of DPDS on mammalian tumor cells and suggests its potential in antiproliferative therapy.

Recently, we evaluated the cytotoxic, prooxidant, genotoxic, and mutagenic properties of this molecule in V79 Chinese lung fibroblast cells (25). When cells were treated with increasing concentrations of DPDS, its cytotoxic activity, as determined using four cell viability endpoints, occurred at doses up to $50 \mu \mathrm{M}$. The MTT reduction was stimulated, which may indicate ROS generation. Accordingly, the treatment of cells for $3 \mathrm{~h}$ with cytotoxic doses of DPDS increased TBARS levels and sensitized cells to oxidative challenge, indicating a pro-oxidant effect. The measurement of total, reduced, and oxidized GSH showed that DPDS can lead to intracellular GSH depletion, with no increase in the oxidation rate in a dose- and time-dependent manner. At the higher doses, DPDS generated DNA strand breaks, as observed using the comet assay. The treatment also induced an increase in the number of binucleated cells in the micronucleus test, showing the mutagenic risk of this molecule at high concentrations. Finally, pre-incubation with $\mathrm{N}$-acetylcysteine, which restored GSH to normal levels, annulled the prooxidant and genotoxic effects of DPDS. These findings show that DPDS-induced oxidative stress and toxicity are closely related to intracellular level of reduced GSH, in agreement with our previous findings in yeast and bacteria.

\section{Reproductive toxicology}

The reproductive and teratogenic effects of DPDS have been evaluated. Favero et al. $(26,27)$ showed that a single subcutaneous injection of 50 and $100 \mathrm{mg} / \mathrm{kg}$ DPDS led to an increased incidence of skeletal variations or anomalies in pregnant Wistar rats, but did not cause externally visible malformations in rat fetuses and did not affect the progeny. DPDS administered either intraperitoneally (acute treatment) or subcutaneously (subchronic treatment) to adult rats also had no reproductive toxicology $(27,28)$. However, recent studies on the effects on embryo-fetal development in dams that were treated subcutaneously with DPDS at 6 to 15 days of pregnancy have shown evidence of toxicity. A decrease in maternal body weight gain, a reduction in fetal weight and crown-rump length, and signs of delayed ossification in the skull, sternebrae and limbs were observed. Exposure of dams to DPDS also resulted in altered placental morphology that may have contributed to an adverse reproductive outcome. The teratogenic and potential reproductive toxicologic aspects of DPDS and the mechanisms involved remain unclear.

\section{Neurotoxicology}

Exposure for 2 months to high doses of DPDS $(250 \mu \mathrm{mol} / \mathrm{kg}$, subcutaneous administration) induced a 3 -fold increase of the total selenium content of the brain, showing that DPDS crosses the blood-brain barrier and brain selenium levels increase in mice after acute and chronic exposure (29,30). This supports the hypothesis that the brain is a potential target for the toxicity of highly lipophilic OS compounds and possibly for their pharmacological and therapeutic actions. The mechanisms underlying the neurotoxicity of OS compounds and their derivatives have been investigated. When neurotoxicologic effects are considered, the toxicity of OS compounds depends on their chemical form, experimental model, age, physiological state, nutrition and dietary interactions, and the route of administration.

In terms of toxicity, the OS compound ebselen $($ Figure 1$)($ molecular weight $=274.2)$ was more toxic than DPDS (molecular weight 
$=310.0)$ in rats acutely treated by the intraperitoneal route (with an $\mathrm{LD}_{50}$ of $1200 \mu \mathrm{mol} /$ $\mathrm{kg}$ for DPDS and of $400 \mu \mathrm{mol} / \mathrm{kg}$ for ebselen) $(31,32)$. In addition, DPDS was more toxic in mice than rats when administered by the intraperitoneal route $\left(\mathrm{LD}_{50}\right.$ of 210 and 1200 $\mu \mathrm{mol} / \mathrm{kg}$, respectively) and had no acute toxic effects when administered by the subcutaneous route (32).

OS compounds have convulsing activity. Intraperitoneal, but not subcutaneous, administration of DPDS provoked seizures in mice but not in rats. In addition, GABAergic allosteric modulators such as diazepam, phenobarbital and muscimol, and a competitive muscarinic antagonist of the acetylcholine receptor, atropine, were able to consistently abolish or reduce the seizure episodes, suggesting that the modulation of one or more neuronal systems can account for the convulsive effect $(33,34)$.

DPDS also affected several neuronal processes. It inhibited the binding of $\left({ }^{3} \mathrm{H}\right)$-glutamate, $\left({ }^{3} \mathrm{H}\right)$-MK-801, and unstable $\left({ }^{3} \mathrm{H}\right)$-guanylyl-imidodiphate (GMP-PNP) to rat synaptic membrane preparations after both in vitro and ex vivo exposure; these are important indicators of glutamatergic system functionality (18). An inhibitory effect on $\left({ }^{3} \mathrm{H}\right)$-glutamate and $\left({ }^{3} \mathrm{H}\right)-\mathrm{MK}-801$ binding indicated that the toxicologic properties of DPDS may be related, at least in part, to the inhibition of the physiological excitatory neurotransmitter system. Experimental results from acute exposure $(25 \mu \mathrm{mol} / \mathrm{kg})$ showed that DPDS drastically reduced $\left({ }^{3} \mathrm{H}\right)$-GMP-PNP binding to G-proteins and the response of adenylate cyclase activity to GMP-PNP, and also increased basal adenylate cyclase activity, suggesting a direct effect on this enzyme. This study also revealed reduction of $\left({ }^{3} \mathrm{H}\right)$-glutamate uptake by brain synaptosomes (18). In human platelets this molecule caused a significant inhibition of $\mathrm{Na}^{+}$-independent glutamate binding to the membrane. In the same study, it inhibited $\left({ }^{3} \mathrm{H}\right)$-glutamate uptake (18).

Calcium channels, mediating $\mathrm{Ca}^{2+}$ influx, play a central role in neurotransmission and chemical agents that potentially interfere with $\mathrm{Ca}^{2+}$ homeostasis are potential toxic agents. DPDS reduced ${ }^{45} \mathrm{Ca}$ influx into isolated nerve endings of rat synaptosomes when a non-depolarizing condition was used or when 4-aminopyridine was used as a depolarizing agent (35). However, the same effects were not observed on excitotoxicity induced by glutamate in an isolated chick retina model (36).

In summary, the neurotoxic effects of DPDS could result from its action at different levels of neural signal transduction pathways, certainly involving other neurotransmitters besides the glutamatergic system.

\section{Pharmacological effects}

The pharmacology of synthetic OS compounds that have been subjected to more than just a biological screening was critically evaluated in a review by Parnham and Graf (37, and see Refs. 1,6). During the past decade, a lot of effort has been directed toward the development of stable OS compounds that could be used as antioxidants, enzyme inhibitors, anti-tumor and anti-infectious agents, cytokine inducers, and immunomodulators (1). In addition, many compounds have been studied. In this section, we explore the potential pharmacological applications of DPDS.

\section{Antioxidant effects}

The essential dietary trace element selenium plays a crucial role in the catalytic center of GPX, an enzyme that catalyzes the reduction of various hydroperoxides by GSH and scavenges ROS, thus protecting cells against oxidative stress (3). However, GPX has some shortcomings, e.g., instability, poor 
availability and high molecular weight. These drawbacks limit its therapeutic application and research has, therefore, centered on developing synthetic drugs with superior performance $(6,38-40)$.

Research in recent years has provided solid evidence for the role of ROS in human disease and this knowledge has led to new ideas for the therapy of a variety of diseases. The concept that selenium-containing molecules may be better nucleophiles than classical antioxidants has led to the design of synthetic OS drugs. Intensive research in OS biochemistry during the last two decades has yielded a variety of compounds with potential antioxidant activity, including ebselen analogues, benzoselenazolinones, selenamide and related derivatives, diaryl diselenides, various tellurides and ditellurides, and the semi-synthetic enzyme selenosubtilisin $(1,3,41)$. The promising compound ebselen is an example of such a molecule; it has antioxidant properties and is known as the most important glutathione peroxidase mimetic agent. Unlike inorganic selenium and selenomethionine, it is not toxic to mammals since it contains bound selenium and thus does not contribute to the cellular selenium pool $(7,39,40)$.

The properties of some synthetic diselenides suggest that the cleavage and reduction of their diselenide bond produces the selenol group, and therefore the diselenides were successful in mimicking GPX (1). Diselenides are good candidates as antioxidant agents because they have some chemical and biochemical characteristics in common with ebselen (18). Of particular importance, DPDS has been shown to be even more active as a GPX mimetic and less toxic to rodents than ebselen $(31,32)$.

The in vitro catalytic activity of DPDS in hydrogen peroxide decomposition was studied by the method that uses benzenethiol as an alternative to GSH. The initial rates of hydrogen peroxide reduction by thiol in the presence of various catalysts were determined in methanol medium by monitoring the UV absorption at $305 \mathrm{~nm}$ due to the formation of DPDS. In this system, DPDS exhibits good initial rates of hydrogen peroxide reduction $(0.55$ against $0.15 \mu \mathrm{M} / \mathrm{min}$ in the absence of catalysts). Indeed, DPDS exhibits GPX-like activity and low-GSH oxidase activity; in the presence of a 10-fold excess of GSH, the diselenide bond in DPDS is reduced to form selenol as the predominant species, which reacts very rapidly with 0.5 equivalents of t-butyl-hydroperoxide (23). The reduction of the diselenide bond in DPDS by GSH may not be an easy reaction, since the redox potential of GSH $(\mathrm{Eo}=-240$ $\mathrm{mV}$ ) is much higher than that of the bond (Eo $=-380 \mathrm{mV})(1,18,23)$.

DPDS, as well as ebselen, reduced the spontaneous and quinolinic acid- and sodium nitroprusside-induced TBARS in rat brain homogenates to basal rates, demonstrating its antioxidant activity $(41,42)$. The antioxidant potential, thiol peroxidase activity and rate of DTT and GSH oxidation have been evaluated in rats and mice. DPDS also efficiently reduced lipid peroxidation in mouse and rat brain, with similar results apart from species differences. It also exhibited high-thiol peroxidase activity and demonstrated better antioxidant potential than the other diselenide substitutes tested $(41,42)$.

DPDS has been recently shown to be effective in restoring acute cadmium-induced oxidative damage in mouse testes, and more effective than the chelating compounds sucimer and 2,3-dimercapto-1-propanesulfonic acid (43-46). Lipid peroxidation has long been considered to be the primary mechanism for cadmium toxicity despite its inability to generate free radicals under physiological conditions. Thus, it is believed that an antioxidant should be one of the important components of an effective treatment 
for cadmium poisoning. Santos and co-workers (44) clearly showed the ability of DPDS therapy to restore enhancement of TBARS levels caused by sub-chronic cadmium exposure in liver and brain of mice. This indicates that the use of DPDS as an antioxidant might be useful in the treatment of cadmium poisoning since it has the capacity to alleviate many of the harmful effects of cadmium. Unexpectedly, DPDS treatment potentiated the testicular damage caused by cadmium in a model using sub-chronic cadmium exposure. This finding again indicated the prooxidant capacity of DPDS, and the two-face properties of OS compounds.

DPDS also protects against inhibition of liver ALA-D during paracetamol intoxication by its antioxidant GPX mimetic activity (18). Recently, an in vitro evaluation of the antioxidant effect of DPDS against sodium nitroprusside-induced lipid peroxidation was carried out. At $2 \mu \mathrm{M}$, this OS molecule significantly protected human platelets and restored GPX activity. These phenomena seem to be related to its thiol peroxidase-like activity (47). Hence DPDS is a promising antioxidant molecule.

However, although the peroxidase-like activity of diselenides may account for their antioxidant properties, the thiol-diselenide exchange catalyzed by chalcogenides may contribute to their toxicologic properties by oxidizing relevant thiol-containing metabolites and proteins without consuming toxic substances like peroxides. Selenides can react with -SH groups, forming selenosulfide or - $\mathrm{SeH}$ and metabolites.

In contrast, using assays such as 1-chloro2,4-dinitrobenzene complex formation and UV absorption, our group has recently shown that DPDS can spontaneously react with $\mathrm{GSH}$, forming stable adducts. This property confers not an antioxidant but a pro-oxidant ability, a common paradox in the biological effects of OS. Thus, the main reactions be- tween DPDS and thiols are oxidation and conjugation. These results have been obtained in vivo using ALA-D inhibition and the investigation of pro-oxidant activity in $S$. cerevisiae, as previously mentioned (21).

\section{Liver and kidney}

The hepatic toxicity of DPDS was the first of its biological properties to be studied. The acute toxicity of DPDS in the male Swiss mouse was enhanced by pre-treatment with phenobarbital, which induces the cytochrome P-450 system. In this study, DPDS decreased hepatic GSH content by $50 \%$ after $1 \mathrm{~h}$ and OS metabolites were found in urine but not in bile or feces (48). DPDS was more toxic to mice than rats when administered by the intraperitoneal route and had no toxic effects when administered subcutaneously (31). However, at higher doses DPDS did not alter hepatic enzyme activity and did not change urea or creatinine parameters, suggesting no renal toxicity (31). Several research groups have demonstrated that liver damage is a therapeutic target of OS compounds, as well as the various clinical conditions in which oxidative stress plays a main role (18).

Pre-treatment with DPDS prevented hepatotoxicity and cellular damage in the rat liver exposed to 2-nitropropane and suggested that the administration of $100 \mu \mathrm{mol} /$ $\mathrm{kg}$ could be effective in mitigating the hazards of 2-nitropropane exposure through its antioxidant properties, increasing superoxide dismutase and catalase activities $(49,50)$. It has also been reported to act as a hepatoprotector in diabetic rats (51). In addition, DPDS protected against acute renal damage, as demonstrated by a decrease in urea levels in rats exposed to 2-nitropropan. The mechanism involved is the increase of catalase and superoxide dismutase activity and again it is correlated with the antioxidant potential 
of DPDS (50). These studies provide practical indications of the benefits of DPDS administration in protecting humans against a variety of hazardous environmental toxicants that induce liver and kidney damage.

\section{Gastric mucosa}

The major side effect of all non-steroidal anti-inflammatory drugs (NSAIDS) is damage to the gastric mucosa. In this respect, it is of considerable importance that OS compounds have no such irritant or damaging effect. DPDS has been recently reported to prevent ethanoland indomethacin-induced ulcers, as well as to inhibit gastric acid secretion in pylorusligated rats. It also protects against mucosal damage by inhibiting the oxidation of the $\mathrm{SH}$ groups of $\mathrm{H}^{+}-\mathrm{K}^{+}$ATPase. This effect on the enzyme responsible for acid secretion can counteract the undesirable side effects caused by NSAIDS. Thus, as anti-inflammatory drugs, OS compounds are versatile with regard to gastric ulcers because not only do they block the inflammatory cascade, which can impair gastric endogenous protective factors against $\mathrm{HCl}$, but also inhibit $\mathrm{HCl}$ secretion. Since the therapeutic approach to a variety of diseases is changing from a single target to a multitarget one, it would be very useful to evaluate the possible synergism of the association of OS compounds with other NSAIDS with respect to the anti-inflammatory response and to the antagonism of gastric ulcer development (18).

\section{Anti-inflammatory activity}

The role of ROS in inflammatory disorders has been the subject of intensive investigation. Considerable effort has been expended in the search for low-toxicity scavengers and inhibitors of ROS. One of the approaches has been to investigate synthetic OS compounds that may be therapeutically beneficial for the treatment of inflammatory diseases.

DPDS displayed the most promising profile against carragenin-induced paw edema; $p$-methoxyphenyl diselenide and $p$-chlorodiphenyl diselenide (Figure 1) were less efficient, $p$-methyldiphenyl diselenide (Figure 1) being the weakest. DPDS has also been demonstrated to be an anti-nociceptive compound, having an effective action in experimental models such as tail-flick, formalin, acetic acid-induced abdominal writhing, and capsaicin. Interestingly, the anti-nociceptive and anti-inflammatory potency of DPDS was higher than that of ebselen and was not related to opioid mechanisms $(34,52)$. Indeed, the mechanisms underlying the analgesic action may be related to serotonergic pathways, but still remain unclear.

\section{Neuroprotection}

New drugs that preserve neuronal integrity, acting after an ischemic insult, are under investigation, including inducible nitric oxide synthase inhibitors, antioxidants, glutamate antagonists, and calcium channel blockers. Data from clinical trials have consistently demonstrated that the OS compound ebselen reduced brain damage in patients with delayed neurological deficits after aneurysmal subarachnoid hemorrhage and improved the outcome of acute ischemic stroke, suggesting that ebselen may be a promising neuroprotective agent $(18,40)$.

In this context, reports on the neuroprotective effects of other GPX mimetics have appeared in the literature in recent years. DPDS has shown a neuroprotective role in an in vitro ischemia model using oxygenglucose deprivation in rat hippocampal slices. It simultaneously prevented two effects in this model: cell death and increase in inducible nitric oxide synthase immunocontent. These effects were dose-dependent and were stronger than those of ebselen (53). 
The effects of systemic administration of DPDS on memory formation were studied using the novel object recognition task in mice. Novel object recognition is a type of non-aversive, non-spatial memory that requires glutamate receptor activation in the hippocampus. The results show that, in acute pre-training, systemic administration of DPDS facilitated novel object recognition in mice without affecting other behavioral parameters such as training performance, shortterm memory or total time spent exploring both objects. In addition, ebselen was shown to induce memory-impairing effects in an inhibitory avoidance task in rats when infused post-training into the dorsal hippocampus (54). However, DPDS facilitated novel object recognition in mice (55).

In neurodegenerative diseases, the cytoskeleton is abnormally assembled and impairment of neurotransmission occurs. $\mathrm{Cu}-$ mulative evidence suggests that neurodegenerative diseases and psychiatric illness are associated with cytoskeleton and loss of sympathetic connectivity and of the ability to transmit incoming axonal information to the somatodendritic domain. DPDS prevented the inhibitory effects of the neurotoxicant methylmercury on the in vitro phosphorylation of intermediate filament cytoskeletal proteins in slices of cerebral cortex of rats, but did not prevent the hyperphosphorylation induced by diphenyl ditelluride $(56,57)$.

Tardive dyskinesia is a motor side effect of long-term treatment with typical neuroleptics; it involves involuntary movements of the face, mouth and tongue, but different parts of the body may be affected. An animal model for tardive dyskinesia is obtained by the acute administration of reserpine to rats; this produces persistent oral dyskinesia. The pathophysiology of the syndrome is unclear, but the neurodegeneration is linked to oxidative stress. Burger and co-workers $(58,59)$ used this model to study the effect of DPDS on behavioral and neurochemical parameters after acute reserpine administration to old rats (15 months). The results showed that the antioxidant properties of DPDS, as well as its anti-inflammatory properties, had only a modest effect in this animal model (58). This OS molecule also reverses haloperidolinduced orofacial dyskinesia, another model for studying this extrapyramidal syndrome, possibly by its antioxidant properties (59).

Recently, using DPDS as a prototype compound, the diselenide-structural analog 3'3-ditrifluoromethyldiphenyl diselenide (DFDD, Figure 4) was developed. DFDD has been shown to attenuate apomorphineinduced stereotypy at a dose which did not affect other behavioral parameters, clearly indicating an antipsychotic potential (60). In addition, this derivative is less toxic than DPDS and does not induce seizures in mice (30). As is the case for DPDS, DFDD decreased lipoperoxidation in mouse and rat brain (41).

\section{Concluding remarks}

Characteristically, all OS compounds (including DPDS) show interesting biological effects in different models and species (Table 2 ), but they also exhibit paradoxical pharmacological properties that cannot be easily explained by the current biochemical methodologies. DPDS has antioxidative properties both in vitro mammalian cell cultures and in murine models, despite the inhibition of ALA-D. On the other hand, DPDS shows pro-oxidative properties in yeast cells, which could be explained by the depletion of cellular glutathione. Another paradoxical effect of DPDS, observed in murine models, is its mechanism of action on the central nervous system. Although DPDS antagonizes the NMDA glutamatergic receptor, which impairs the formation of memory, this com- 
Table 2. Pharmacology and toxicology of diphenyl diselenide in several biological models.

\begin{tabular}{|c|c|c|c|c|c|}
\hline \multicolumn{3}{|c|}{ Pharmacology } & \multicolumn{3}{|c|}{ Toxicology } \\
\hline Effect & Model & References & Effect & Model & References \\
\hline \multirow[t]{2}{*}{ Antioxidative effects } & $\begin{array}{l}\text { Chemical systems: glutathione } \\
\text { peroxidase and thiol peroxidase } \\
\text { activities; protective against sodium } \\
\text { nitroprusside-induced lipid } \\
\text { peroxidation }\end{array}$ & $1,18,23$ & $\begin{array}{l}\text { Thiol group } \\
\text { oxidation }\end{array}$ & Chemical systems & 8 \\
\hline & $\begin{array}{l}\text { Murine models: quinolinic acid- } \\
\text { and sodium nitroprusside-induced } \\
\text { TBARS in rat brain homogenates } \\
\text { and against oxidative stress induced } \\
\text { by cadmium chloride }\end{array}$ & $18,41-46$ & & $\begin{array}{l}\text { Murine models } \\
\text { Inhibition of ALA-D } \\
\text { in several organs } \\
\text { and tissues in } \\
\text { mammals }\end{array}$ & $\begin{array}{l}14,16 \\
17-19\end{array}$ \\
\hline \multirow[t]{2}{*}{ Neuroprotective agent } & $\begin{array}{l}\text { In vitro ischemia model using } \\
\text { oxygen-glucose deprivation in rat } \\
\text { hippocampal slices }\end{array}$ & 53 & $\begin{array}{l}\text { GSH } \\
\text { depletion }\end{array}$ & $\begin{array}{l}\text { Chemical systems: } \\
\text { CDNB complexation and } \\
\text { GSH-DPDS interaction }\end{array}$ & 16,21 \\
\hline & $\begin{array}{l}\text { Protection against methylmercury } \\
\text { effects on the in vitro phosphorylation } \\
\text { of intermediate filament cytoskeletal } \\
\text { proteins in slices of rat cerebral cortex }\end{array}$ & 56,57 & & $\begin{array}{l}\text { Yeast strains (wild-type } \\
\text { and antioxidant defense } \\
\text { defective strains) }\end{array}$ & 21 \\
\hline Hepatoprotective effect & $\begin{array}{l}\text { Hepatotoxicity induced by } \\
\text { 2-nitropropane in rats }\end{array}$ & 49,50 & & V79 cell culture & 25 \\
\hline \multirow[t]{2}{*}{$\begin{array}{l}\text { Gastric mucosal } \\
\text { protection }\end{array}$} & $\begin{array}{l}\text { Ethanol and indomethacin-induced } \\
\text { ulcers in rats }\end{array}$ & 18 & $\begin{array}{l}\text { Neurotoxic } \\
\text { effects }\end{array}$ & $\begin{array}{l}\text { Impairment of glutamatergic } \\
\text { transmission in mice and rats }\end{array}$ & $18,33,34$ \\
\hline & Pylorus-ligated rats & 18 & $\begin{array}{l}\text { Genotoxic and } \\
\text { mutagenic }\end{array}$ & Ames test & 4 \\
\hline Cognitive enhancer & Novel object recognition task in mice & 55 & & $\begin{array}{l}\text { Mutagenesis and } \\
\text { recombinogenesis in yeast }\end{array}$ & 4 \\
\hline Anti-inflammatory & $\begin{array}{l}\text { Carragenin-induced paw edema in } \\
\text { mice }\end{array}$ & 34,52 & & $\begin{array}{l}\text { Comet assay and micro- } \\
\text { nucleus evaluation in } \\
\text { V79 cells }\end{array}$ & 25 \\
\hline \multirow[t]{4}{*}{ Antinociceptive properties } & Tail-flick test in mice & 34,52 & & Comet assay in MCF7 cells & $\begin{array}{l}\text { Present } \\
\text { study }\end{array}$ \\
\hline & $\begin{array}{l}\text { Acetic acid-induced abdominal } \\
\text { writhing in mice }\end{array}$ & 34,52 & $\begin{array}{l}\text { Teratogenic } \\
\text { evidence }\end{array}$ & Murine models & $26-28$ \\
\hline & $\begin{array}{l}\text { Formalin-induced abdominal writhing } \\
\text { in mice }\end{array}$ & 34,52 & & & \\
\hline & Capsaicin effects in mice & 34,52 & & & \\
\hline \multirow[t]{2}{*}{$\begin{array}{l}\text { Effect in animal models } \\
\text { of tardive dyskinesia }\end{array}$} & $\begin{array}{l}\text { Acute administration of } \\
\text { reserpine to old rats }\end{array}$ & 58 & & & \\
\hline & $\begin{array}{l}\text { Haloperidol-induced orofacial } \\
\text { dyskinesia in rats }\end{array}$ & 59 & & & \\
\hline
\end{tabular}

TBARS = thiobarbituric acid reactive substances; ALA-D = $\delta$-aminolevulinate dehydratase; $G S H=$ glutathione; CDNB = 1-chloro-2,4-dinitrobenzene; DPDS = diphenyl diselenide. 
pound is able to stimulate memory formation in mice. Unfortunately, the biochemical principles that drive this phenomenon are largely unknown and more empirical data are necessary to conclude how DPDS act on the nervous system.

Taking into account all the biological effects of DPDS and the other OS compounds reviewed here, more experiments are needed to elucidate how they act on eukaryotic cells. Once a clearer picture emerges, it might be possible to synthesize new OS substances specifically applicable to clinically important metabolic routes.

\section{Acknowledgments}

The authors thank Dr. Christine Gaylarde (Universidade Federal do Rio Grande do Sul, Porto Alegre, RS, Brazil), Dr. Martin Brendel (Universidade Estadual de Santa Cruz, Ilhéus, BA, Brazil) and Dr. Cristina Pungartnick (Universidade Estadual de Santa Cruz, Ilhéus, BA, Brazil) for critically reading the manuscript.

\section{References}

1. Mugesh G, du Mont WW, Sies H. Chemistry of biologically important synthetic organoselenium compounds. Chem Rev 2001; 101: 21252179.

2. Birringer M, Pilawa S, Flohe L. Trends in selenium biochemistry. Nat Prod Rep 2002; 19: 693-718.

3. Brenneisen $\mathrm{P}$, Steinbrenner $\mathrm{H}$, Sies $\mathrm{H}$. Selenium, oxidative stress, and health aspects. Mol Aspects Med 2005; 26: 256-267.

4. Rosa RM, Sulzbacher K, Picada JN, Roesler R, Saffi J, Brendel M, et al. Genotoxicity of diphenyl diselenide in bacteria and yeast. Mutat Res 2004; 563: 107-115.

5. Tsen CC, Tappel AL. Catalytic oxidation of glutathione and other sulfhydryl compounds by selenite. J Biol Chem 1958; 233: 12301232.

6. Aboul-Fadl T. Selenium derivatives as cancer preventive agents. Curr Med Chem Anticancer Agents 2005; 5: 637-652.

7. Ganther HE. Selenium metabolism and mechanisms of cancer prevention. Adv Exp Med Biol 2001; 492: 119-130.

8. Levander OA, Morris VC, Higgs DJ. Selenium as a catalyst for the reduction of cytochrome $\mathrm{c}$ by glutathione. Biochemistry 1973; 12 : 4591-4595.

9. Chen GP, Ziegler DM. Liver microsome and flavin-containing monooxygenase catalyzed oxidation of organic selenium compounds. Arch Biochem Biophys 1994; 312: 566-572.

10. Ganther HE. Reduction of the selenotrisulfide derivative of glutathione to a persulfide analog by glutathione reductase. Biochemistry 1971; 10: 4089-4098.

11. Jaffe EK. Porphobilinogen synthase, the first source of heme's asymmetry. J Bioenerg Biomembr 1995; 27: 169-179.

12. Markham GD, Myers CB, Harris KA Jr, Volin M, Jaffe EK. Spatial proximity and sequence localization of the reactive sulfhydryls of porphobilinogen synthase. Protein Sci 1993; 2: 71-79.

13. Emanuelli T, Pagel FW, Alves LB, Regner A, Souza DO. Inhibition of adenylate cyclase activity by 5 -aminolevulinic acid in rat and human brain. Neurochem Int 2001; 38: 213-218.

14. Barbosa NB, Rocha JB, Zeni G, Emanuelli T, Beque MC, Braga AL. Effect of organic forms of selenium on delta-aminolevulinate dehydratase from liver, kidney, and brain of adult rats. Toxicol Appl
Pharmacol 1998; 149: 243-253.

15. Folmer V, Bolzan RC, Farina M, Zeni G, Nogueira CW, Emanuelli T, et al. Mechanism of delta-aminolevulinate dehydratase inhibition by phenyl selenoacetylene involves its conversion to diphenyl diselenide. Toxicology 2005; 206: 403-411.

16. Maciel EN, Bolzan RC, Braga AL, Rocha JB. Diphenyl diselenide and diphenyl ditelluride differentially affect delta-aminolevulinate dehydratase from liver, kidney, and brain of mice. J Biochem Mol Toxicol 2000; 14: 310-319.

17. Farina M, Barbosa NB, Nogueira CW, Folmer V, Zeni G, Andrade $\mathrm{LH}$, et al. Reaction of diphenyl diselenide with hydrogen peroxide and inhibition of delta-aminolevulinate dehydratase from rat liver and cucumber leaves. Braz J Med Biol Res 2002; 35: 623-631.

18. Nogueira CW, Zeni G, Rocha JB. Organoselenium and organotellurium compounds: toxicology and pharmacology. Chem Rev 2004; 104: 6255-6285.

19. Nogueira CW, Borges VC, Zeni G, Rocha JB. Organochalcogens effects on delta-aminolevulinate dehydratase activity from human erythrocytic cells in vitro. Toxicology 2003; 191: 169-178.

20. Fachinetto R, Pivetta LA, Farina M, Pereira RP, Nogueira CW, Rocha JB. Effects of ethanol and diphenyl diselenide exposure on the activity of delta-aminolevulinate dehydratase from mouse liver and brain. Food Chem Toxicol 2006; 44: 588-594.

21. Moreira RR, de Oliveira RB, Saffi J, Braga AL, Roesler R, Dal-Pizzol $\mathrm{F}$, et al. Pro-oxidant action of diphenyl diselenide in the yeast Saccharomyces cerevisiae exposed to ROS-generating conditions. Life Sci 2005; 77: 2398-2411.

22. Estrela JM, Ortega A, Obrador E. Glutathione in cancer biology and therapy. Crit Rev Clin Lab Sci 2006; 43: 143-181.

23. Mugesh G, Panda A, Singh HB, Punekar NS, Butcher RJ. Glutathione peroxidase-like antioxidant activity of diaryl diselenides: a mechanistic study. J Am Chem Soc 2001; 123: 839-850.

24. Noll DM, Mason TM, Miller PS. Formation and repair of interstrand cross-links in DNA. Chem Rev 2006; 106: 277-301.

25. Rosa R, do Nascimento Picada J, Saffi J, Henriques J. Cytotoxic, genotoxic and mutagenic effects of diphenyl diselenide in Chinese hamster lung fibroblasts. Mutat Res 2006; 628: 87-98. 
26. Favero AM, Weis SN, Stangherlin EC, Zeni G, Rocha JB, Nogueira CW. Teratogenic effects of diphenyl diselenide in Wistar rats. Reprod Toxicol 2005; 20: 561-568.

27. Favero AM, Weis SN, Stangherlin EC, Zeni G, Rocha JB, Nogueira CW. Adult male rats sub-chronically exposed to diphenyl diselenide: Effects on their progeny. Reprod Toxicol 2007; 23: 119-123.

28. Stangherlin EC, Favero AM, Weis SN, Zeni G, Rocha JB, Nogueira $\mathrm{CW}$. Assessment of reproductive toxicity in male rats following acute and sub-chronic exposures to diphenyl diselenide and diphenyl ditelluride. Food Chem Toxicol 2006; 44: 662-669.

29. Maciel EN, Flores EM, Rocha JB, Folmer V. Comparative deposition of diphenyl diselenide in liver, kidney, and brain of mice. Bull Environ Contam Toxicol 2003; 70: 470-476.

30. Jacques-Silva MC, Nogueira CW, Broch LC, Flores EM, Rocha JB. Diphenyl diselenide and ascorbic acid changes deposition of selenium and ascorbic acid in liver and brain of mice. Pharmacol Toxicol 2001; 88: 119-125.

31. Meotti FC, Borges VC, Zeni G, Rocha JB, Nogueira CW. Potential renal and hepatic toxicity of diphenyl diselenide, diphenyl ditelluride and Ebselen for rats and mice. Toxicol Lett 2003; 143: 9-16.

32. Nogueira CW, Meotti FC, Curte E, Pilissao C, Zeni G, Rocha JB. Investigations into the potential neurotoxicity induced by diselenides in mice and rats. Toxicology 2003; 183: 29-37.

33. Brito VB, Folmer V, Puntel GO, Fachinetto R, Soares JC, Zeni G, et al. Diphenyl diselenide and 2,3-dimercaptopropanol increase the PTZ-induced chemical seizure and mortality in mice. Brain Res Bull 2006; 68: 414-418.

34. Nogueira CW, Quinhones EB, Jung EA, Zeni G, Rocha JB. Antiinflammatory and antinociceptive activity of diphenyl diselenide. Inflamm Res 2003; 52: 56-63.

35. Moretto MB, Rossato JI, Nogueira CW, Zeni G, Rocha JB. Voltagedependent ebselen and diorganochalcogenides inhibition of $45 \mathrm{Ca}^{2+}$ influx into brain synaptosomes. J Biochem Mol Toxicol 2003; 17 : 154-160.

36. Centuriao FB, Corte CL, Paixao MW, Braga AL, Zeni G, Emanuelli $\mathrm{T}$, et al. Effect of ebselen and organochalcogenides on excitotoxicity induced by glutamate in isolated chick retina. Brain Res 2005; 1039 : 146-152.

37. Parnham MJ, Graf E. Pharmacology of synthetic organic selenium compounds. Prog Drug Res 1991; 36: 9-47.

38. Geoghegan M, McAuley D, Eaton S, Powell-Tuck J. Selenium in critical illness. Curr Opin Crit Care 2006; 12: 136-141.

39. Sies H. Ebselen, a selenoorganic compound as glutathione peroxidase mimic. Free Radic Biol Med 1993; 14: 313-323.

40. Schewe T. Molecular actions of ebselen - an antiinflammatory antioxidant. Gen Pharmacol 1995; 26: 1153-1169.

41. Rossato JI, Ketzer LA, Centuriao FB, Silva SJ, Ludtke DS, Zeni G, et al. Antioxidant properties of new chalcogenides against lipid peroxidation in rat brain. Neurochem Res 2002; 27: 297-303.

42. Meotti FC, Stangherlin EC, Zeni G, Nogueira CW, Rocha JB. Protective role of aryl and alkyl diselenides on lipid peroxidation. Environ Res 2004; 94: 276-282.

43. Santos FW, Oro T, Zeni G, Rocha JB, do Nascimento PC, Nogueira $\mathrm{CW}$. Cadmium induced testicular damage and its response to administration of succimer and diphenyl diselenide in mice. Toxicol Lett 2004; 152: 255-263.

44. Santos FW, Zeni G, Rocha JB, do Nascimento PC, Marques MS, Nogueira CW. Efficacy of 2,3-dimercapto-1-propanesulfonic acid (DMPS) and diphenyl diselenide on cadmium induced testicular damage in mice. Food Chem Toxicol 2005; 43: 1723-1730.

45. Santos FW, Zeni G, Rocha JB, Weis SN, Fachinetto JM, Favero AM, et al. Diphenyl diselenide reverses cadmium-induced oxidative damage on mice tissues. Chem Biol Interact 2005; 151: 159-165.

46. Santos FW, Graca DL, Zeni G, Rocha JB, Weis SN, Favero AM, et al. Sub-chronic administration of diphenyl diselenide potentiates cadmium-induced testicular damage in mice. Reprod Toxicol 2006 ; 22: 546-550.

47. Posser $T$, Moretto MB, Dafre AL, Farina M, da Rocha JB, Nogueira $\mathrm{CW}$, et al. Antioxidant effect of diphenyl diselenide against sodium nitroprusside (SNP) induced lipid peroxidation in human platelets and erythrocyte membranes: an in vitro evaluation. Chem Biol Interact 2006; 164: 126-135.

48. Adams WJ Jr, Kocsis JJ, Snyder R. Acute toxicity and urinary excretion of diphenyldiselenide. Toxicol Lett 1989; 48: 301-310.

49. Borges LP, Borges VC, Moro AV, Nogueira CW, Rocha JB, Zeni G. Protective effect of diphenyl diselenide on acute liver damage induced by 2-nitropropane in rats. Toxicology 2005; 210: 1-8.

50. Borges LP, Nogueira CW, Panatieri RB, Rocha JB, Zeni G. Acute liver damage induced by 2-nitropropane in rats: effect of diphenyl diselenide on antioxidant defenses. Chem Biol Interact 2006; 160: 99-107.

51. Barbosa NB, Rocha JB, Wondracek DC, Perottoni J, Zeni G, Nogueira CW. Diphenyl diselenide reduces temporarily hyperglycemia: possible relationship with oxidative stress. Chem Biol Interact 2006; 163: 230-238.

52. Savegnago L, Pinto LG, Jesse CR, Alves D, Rocha JB, Nogueira $\mathrm{CW}$, et al. Antinociceptive properties of diphenyl diselenide: evidences for the mechanism of action. Eur J Pharmacol 2007; 555: 129-138.

53. Ghisleni G, Porciuncula LO, Cimarosti H, Batista TR, Salbego CG, Souza DO. Diphenyl diselenide protects rat hippocampal slices submitted to oxygen-glucose deprivation and diminishes inducible nitric oxide synthase immunocontent. Brain Res 2003; 986: 196 199.

54. Porciuncula LO, Schmidt AP, Coitinho AS, Vinade L, Izquierdo I, Rocha JB, et al. Intrahippocampal infusion of ebselen impairs retention of an inhibitory avoidance task in rats. Eur $J$ Pharmacol 2002; 451: 165-169.

55. Rosa RM, Flores DG, Appelt HR, Braga AL, Henriques JA, Roesler R. Facilitation of long-term object recognition memory by pretraining administration of diphenyl diselenide in mice. Neurosci Lett 2003; 341: 217-220.

56. Moretto MB, Funchal C, Zeni G, Rocha JB, Pessoa-Pureur R. Organoselenium compounds prevent hyperphosphorylation of cytoskeletal proteins induced by the neurotoxic agent diphenyl ditelluride in cerebral cortex of young rats. Toxicology 2005; 210: 213-222.

57. Funchal C, Moretto MB, Vivian L, Zeni G, Rocha JB, Pessoa-Pureur R. Diphenyl ditelluride- and methylmercury-induced hyperphosphorylation of the high molecular weight neurofilament subunit is prevented by organoselenium compounds in cerebral cortex of young rats. Toxicology 2006; 222: 143-153.

58. Burger M, Fachinetto R, Calegari L, Paixao MW, Braga AL, Rocha JB. Effects of age on reserpine-induced orofacial dyskinesia and possible protection of diphenyl diselenide. Brain Res Bull 2004; 64 : 339-345.

59. Burger ME, Fachinetto R, Wagner C, Perottoni J, Pereira RP, Zeni $G$, et al. Effects of diphenyl-diselenide on orofacial dyskinesia model in rats. Brain Res Bull 2006; 70: 165-170.

60. Machado MS, Rosa RM, Dantas AS, Reolon GK, Appelt HR, Braga $A L$, et al. An organic selenium compound attenuates apomorphineinduced stereotypy in mice. Neurosci Lett 2006; 410: 198-202. 